\title{
Comparative evidence of the consumption from fast-food restaurants between normal-weight and obese Saudi schoolchildren
}

\author{
Hmidan A Alturki ${ }^{1,2, *}$, Denise SK Brookes ${ }^{1}$ and Peter SW Davies ${ }^{1}$ \\ ${ }^{1}$ Children's Nutrition Research Centre, Child Health Research Centre, Centre for Children's Health Research, \\ University of Queensland, Level 6/62 Graham Street, South Brisbane, QLD 4101, Australia: ${ }^{2}$ King Abdulaziz City \\ for Science and Technology, PO Box 6086, Riyadh 11442, Kingdom of Saudi Arabia
}

Submitted 4 September 2017: Final revision received 23 February 2018: Accepted 2 March 2018: First published online 6 April 2018

\begin{abstract}
Objective: To provide an in-depth analysis of the relationship between obesity and fast-food consumption by comparing urban obese and normal-weight Saudi Arabian children.

Design: A multicentre cross-sectional study was conducted from December 2015 to March 2016. Participants were divided into two groups (normal weight and obese) and further stratified by sex. Groups were randomly selected using a multistage stratified cluster-sampling technique. A self-paced questionnaire was used to collect data relating to food consumption. Weight height and waist circumference were measured and bioelectrical impedance analysis was performed in all children.

Setting: Capital of Saudi Arabia, Riyadh.

Subjects: Children aged 9.00-11.99 years ( $n$ 1023).

Results: Compared with normal-weight groups, intake frequency of fast food/ week was higher among the obese groups $(P<0.001)$, irrespective of fast-food consumption outside $(P<0.001)$ or inside $(P<0.001)$ the home; and larger portion sizes were preferred in obese groups $(P<0 \cdot 001)$. Families eating fast-food meals together was a protective factor against obesity (OR; 95\% CI: 2.67; 1.44, 4.96, $P<0.001)$, with similar results for families ordering from a 'healthy meals menu' for their children $(1.90 ; 1.24,2.90, P=0.002)$. Taste of fast foods $(P=0.021)$, child-friendly menu $(P=0 \cdot 020)$ and meal cost $(P<0 \cdot 001)$ were identified as main reasons why parents took their children to fast-food restaurants; these data were replicated for parents with obese boys, but not girls.

Conclusions: Development of effective interventions to reduce fast-food consumption in Saudi Arabian schoolchildren requires greater research-based evidence of fast-food consumption habits and practices associated with increased childhood obesity.
\end{abstract}

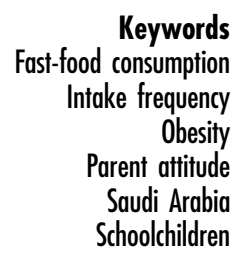

Obesity in children is reaching disturbing proportions in many developed and developing countries, posing an urgent and complex public health challenge ${ }^{(1)}$. One country identified as facing a high prevalence of childhood obesity is Saudi Arabia ${ }^{(2)}$. The prevalence of overweight and obesity in upper primary-school children has increased significantly in the last few years, from $16.8 \%$ in $2002^{(3)}$ to $37 \cdot 0 \%$ in $2010^{(4)}$. The increased obesity among Saudi Arabian children has been commensurate with the increased consumption of fast foods ${ }^{(5)}$. The high rate of obesity in children and youth can be associated with the habit of frequent eating at fast-food restaurants and foregoing home-cooked meals ${ }^{(6)}$. Children who frequently eat at fast-food restaurants are shown to have a higher intakes of fatty foods, unwanted energy, sugar-sweetened drinks, sweet/savoury snacks and highly salted foods, and reduced intakes of dietary fibre, milk, water and healthy foods such as fruits and vegetables ${ }^{(6,7)}$. Therefore, eating foods prepared at restaurants, especially fast-foods outlets, adversely effects the achievement of dietary requirements $^{(8)}$ and, consequently, the health of the population, especially in children.

Lifestyle in Saudi Arabia has undergone dramatic changes in the past few decades due to the vast economic growth in the Arabian Gulf, resulting in a cultural shift towards a more westernised and/or developed-world standard of living, to directly impact food choices and eating habits ${ }^{(9)}$. This has led to an increased consumption 
of fast foods by Saudi Arabians, particularly young peo$\mathrm{ple}^{(5)}$. Furthermore, the higher consumer demand has resulted in more fast-food restaurants opening, particularly in the major cities. Presently, fast-food restaurants can be seen everywhere. Anecdotally, most Saudi Arabian families, especially those with children, prefer to eat at restaurants as they are viewed as the best places to spend leisure time, especially during evenings, weekends and holidays. A main reason is the extreme climate (very hot and/or very cold) and an absence or lack of indoor recreational places for families. Moreover, due to increasing incomes, Saudi Arabian people can easily afford to eat out regularly ${ }^{(9)}$.

Primarily, young individuals are the main consumers of fast-food meals as opposed to older individuals ${ }^{(10)}$. A rise in fast-food consumption is reported among children aged 9-19 years as they become more independent of parental influences $^{(6,11)}$. As $56 \cdot 4 \%$ of the Saudi Arabian population is under the age of 18 years ${ }^{(12)}$, and parents play an integral role in their eating habits, gathering evidence-based data on how the consumption of fast foods can affect obesity in children of primary-school age is critically needed. Limited research in this area has been documented in Saudi Arabia and focuses on the intake of fast foods ${ }^{(5,13,14)}$, without evidencing fast-food knowledge, attitudes and practices and/or including the parent's role in these issues. Therefore, an important aim of our study was to investigate and obtain information on consumption of fast foods and related factors that may affect Saudi Arabian boys' and girls' body weight status, by using comparative data between BMI-classified normal-weight and obese children; intending to elucidate treatment strategies that may be achieved. To our knowledge, the present study is the first of its kind to be conducted in Saudi Arabia to provide comparative data of fast-food consumption factors and the role of parents in obese and normal-weight, upper primary-school children in urban areas of the country.

\section{Methods}

\section{Setting}

The study was implemented in Riyadh, as it is the best representative city for the Saudi Arabian population in many ways ${ }^{(15)}$. Riyadh's population is typically made up of people from all different Saudi Arabian provinces. Therefore, it was a statistically good choice to provide a wider demographic representation. Convenience samples of participants were selected from each of the five geographical areas (north, south, east, west, centre) to cover most of Riyadh city. All data were gathered over a period of 4 months, December 2015 to March 2016.

\section{Study design and sampling}

Our study is a cross-sectional, convenience sample of volunteer children who participated after having secured parental consent. Logistic regression was used to explore the associations between the dependant variables, obese and normal weight (based on BMI classification), and other variables. A sample size of $n 200$ in each group, for each sex, would allow for a maximum of sixteen independent variables within a logistic regression, which is within the accepted ratio of subjects to independent variables (i.e. between twelve and fifteen subjects per independent variable). Other analyses included a comparison of answers, to various questions asked of the families, between those with an obese child and those with a normal-weight child, expressed as a percentage.

\section{Data collection}

The data were collected from primary schools of boys and girls in grades 4 (age 9-10 years), 5 (age 10-11 years) and 6 (age 11-12 years). Riyadh is divided into five districts. Two primary governmental schools (one for boys and one for girls) were randomly selected from each of the five districts to take part in the study. Furthermore, two private schools were randomly selected (one boys' school and one girls' school). Overall, a total of twelve schools were selected to participate in the study. Nevertheless, to maximise data collection on obese children, additional recruitment occurred in both public and private obesity clinics. The public clinic recruitment occurred during the day, and the free private clinic was held in the evenings, catering for parents and children unable to attend day sessions due to time constraints. During the recruitment, all children provided verbal assent as well as obtaining informed consent in writing from their parents. No measurements were taken from any child who did not provide assent.

\section{Selection criteria}

All participants meet the inclusion criteria of: (i) child between the ages of 9.00 and 11.99 years; (ii) Saudi Arabian nationality; and (iii) living in Riyadh city. Moreover, (iv) two groups were recruited according to BMI-for-age percentile based on the Centers for Disease Control and Prevention data $^{(16)}$ : an obese group (BMI $>95$ th percentile) and a normal-weight group (BMI between 25th and 75th percentile). The 75 th percentile was used as the BMI cut-off point, as opposed to the 85th percentile, to ensure a clear distinction between normal-weight and obese children.

\section{Anthropometric measurements}

Anthropometric variables for both groups (obese and normal weight) were as follows: height, weight and waist circumference were measured, and BMI $\left(\mathrm{kg} / \mathrm{m}^{2}\right)$ was calculated using measured height and weight. Measurements were performed by trained data collectors, using standard protocols. Weight was recorded to the nearest $100 \mathrm{~g}$, without excess outer clothing and shoes, using a calibrated portable Seca scale. Height was measured to the nearest centimetre using the same device, with participants standing upright without shoes. Waist circumference 
measurement was recorded to the nearest $0.5 \mathrm{~cm}$ at the level of the umbilicus, and was classified according the Centers for Disease Control and Prevention's anthropometric reference percentile data for children ${ }^{(17)}$.

\section{Body composition assessment}

A bioelectrical impedance analysis device (Omron BF511, model HBF-511B-E) was used as a fast, easy-to-use, portable and accurate method of body composition assessment ${ }^{(18)}$, as required for our cohort. The Omron BF511 device introduces a small alternating current $(500 \mu \mathrm{A})$ into the body at a frequency of $50 \mathrm{kHz}$. By measuring the voltage drop across the body, a prediction of the conducting medium (i.e. total body water) can be made, allowing the fat-free mass to be calculated along with the fat mass. Additionally, bioelectrical impedance analysis has been shown to be more reliable than traditional skinfold thickness measurement ${ }^{(19)}$. The classification levels of body fat percentage (\%BF) used in our study were based on McCarthy et al. ${ }^{(20)}$. For the 9-12 years age group, \%BF was considered low when $<16 \cdot 1 \%$; normal when between $16 \cdot 1$ and $32 \cdot 4 \%$; and high when between 32.5 and $35.3 \%$. $\%$ BF over $35.4 \%$ was considered very high.

\section{Data processing and statistical analysis}

Data in each questionnaire, at each collection centre, were checked twice: initially by the assistant data collectors (dietitians), with a final check being completed by the main researcher (H.A.A.). The data were entered electronically, using standardised entry codes written on an SPSS data file. All data were analysed using the statistical software package IBM SPSS Statistics version 24. Descriptive statistics are presented as means and SD, or proportions. The main analysis was a comparative analysis between the two groups (obese and normal weight) and stratified by sex. The $t$ test was used to determine the distribution of ages in the obese and normal-weight groups; while the $\chi^{2}$ test was used to determine any significant associations between the obese or normal-weight group, and the dependent variables, including the participating child's fast-food intake habits, parent engagement in the child's intake from fast-food restaurants and reasons parents chose fast-food restaurants for their children's meals. Logistic regression was performed to assess the impact of these aforementioned variables on the likelihood that children would be categorised as obese. The level of significance was set at $P<0 \cdot 05$.

\section{Dietary data}

All fast-food intake habits and behaviour questionnaires used in our study are widely acceptable, valid and reliable $^{(21-23)}$. Data on food consumption trends were collected using a variety of questionnaires, with focus questions gathering data on weekly consumption frequency of fast foods. Specifics of the frequency of eating fast foods per week were eating out (restaurants) and/or eating in (home). For the purposes of our research, 'fast food' was descriptive primarily of any food sourced from any international food chain, such as McDonald's, Burger King, Hardee's, KFC, Pizza Hut and Five Guys, as well as popular local chains like Herfy, Kudu, Al Baik and Shawarmer.

Other questionnaires included details of portion sizes that children preferred to consume at fast-food restaurants. In addition, parent/family engagement in their child's consumption of fast foods (including whether the participating family normally ate fast-food meals together; identifying the family member who normally orders the fast-food meal for the child; if the parent normally decides the type/size of the meal; and if parents regularly chose fast-food restaurant meals to reward to their child/ children) and a collection of reasons for parents to take their children to fast-food restaurants were included. Availability of healthy options and menu nutrition labels at fast-food restaurant was also collected. These questionnaire booklets, together with the written informed consent forms, were sent to parents/guardian to complete at home.

\section{Results}

A total of 1200 eligible children were consented by their parents to take part in the study, following written informed consent. The total number of children accepted into the cohort who met our eligibility criteria was 1023 . This final cohort represented different geographical areas of Riyadh and was group-stratified as 497 obese and 526 normal-weight children.

The number of children in each year of age and their anthropometric data are shown in Table 1. The data are shown classified according to obese or normal weight and stratified by sex. There was no significant difference in age distribution for boys and girls in the obese and normal weight groups. Waist circumference and \%BF for the normal weight and obese groups reflected the normal range of parameters for the respective group. The study cohort was clearly identified and selected; therefore, as expected, differences in weight, height, waist circumference, \%BF and BMI between the groups, and stratified by sex, were statistically significant $(P<0 \cdot 001)$.

The frequency of fast-food intake, frequency of eating out (restaurants) as opposed to eating in (home) and the preferred portion size, classified by BMI and sex, are shown in Table 2, along with the odds of children being categorised as obese. Increased frequency of eating fast foods per week, irrespective of being out or at home, was positively associated with an increased risk of being obese. These relationships were statistically significant between groups and sex $(P<0 \cdot 001)$. Increased frequency of children eating fast foods outside the home was shown in the obese group $(\mathrm{OR}=0.45 ; 95 \%$ CI $0.35,0.59)$, 
especially boys $(\mathrm{OR}=0.25 ; 95 \%$ CI $0 \cdot 16,0 \cdot 37)$; however, no relationship was found between BMI and the frequency of eating fast foods at home $(P=0 \cdot 153)$. Interestingly, most children, in both groups, preferred to eat fast foods at home.

A larger portion size chosen, when eating fast foods, was positively related to being obese as a group $(P=0.038)$ and the risk of being obese (OR $=2 \cdot 61 ; 95 \%$ CI $1 \cdot 03,6 \cdot 61)$, but not when stratified by sex. In contrast, for specific foods, selecting a larger portion of French fries was positively associated with being obese as a group (OR $=4.95 ; 95 \% \mathrm{CI}$ 1.94, 12.63; $P<0.001$ ) and stratified by sex (Table 2 ). The same statistical significance was also found if a larger soft drink size was chosen with the fast-food meal in the normal weight compared with the obese group $(P<0 \cdot 001)$, especially in boys $(P=0 \cdot 000)$, meaning an increased portion size corresponds to an increase in obesity.

The data on parental and adult family members' involvement dealing with, monitoring and controlling the behaviour of their children when eating at fast-food restaurants are shown in Table 3, along with the odds of children being categorised as obese. There was no association between parents offering to go to a fast-food restaurant, as a child's reward, and weight status $(P=0.317)$. The children were more likely to be of normal weight if the parents and/or families: ate fast-food meals together (OR= $2 \cdot 67 ; 95 \%$ CI 1.44, 4.96); decided the type and/or size of the fast-food meal (OR=0.40; 95\% CI, 0.19, 0.85); and ordered from the 'healthy meals menu' (OR $=7.90$; 95\% CI, 1.24, 2.90) for their child, especially for boys (Table 3). Who normally ordered the fast-food meal for the child (mother, father, child or others) varied between groups; comparing boys, and groups, only, these relationships were statistically significant $(P<0 \cdot 001)$. As the children became more independent in ordering for themselves, this was shown as an increased risk factor to be obese (OR $=4 \cdot 84 ; 95 \%$ CI $2 \cdot 09$, 11-16). However, no statistically significant relationships were found in girls $(P=0 \cdot 072)$. Our data showed no associations between a nutritional label being available on the menu at fast-food restaurants frequented by parents with their children, and BMI, except where parents 'don't see/ notice' such information, particularly in boys $(\mathrm{OR}=3 \cdot 19$; 95\% CI 1.03, 9.86; $P=0 \cdot 016$ ).

Reasons why parents chose to take their children to fastfood restaurants appear in Table 4, along with the odds of children to be categorised as obese. Our data varied between the groups, especially in boys. The cost of fastfood meals (OR $=7.44 ; 95 \%$ CI 4.08, 13.57; $P<0.001$ ), children liking the taste of the food (OR=1.33; 95\% CI $1.04,1.71 ; P=0.021)$ and fast-food restaurants having child-friendly menus (OR $=1.72 ; 95 \%$ CI 1.08, 2.73; $P=0.020)$ were common factors among the obese group, especially the boys. Conversely, reasons such as a fast-food restaurant entertaining the child, child-friendly restaurants, quick service time and convenience did not influence the results between the normal weight and 
Table 2 Association of fast-food intake with child weight status, according to sex and categorisation as normal weight or obese*, among children aged 9.00-11.99 years ( $n$ 1023), Riyadh, Saudi Arabia, December 2015-March 2016

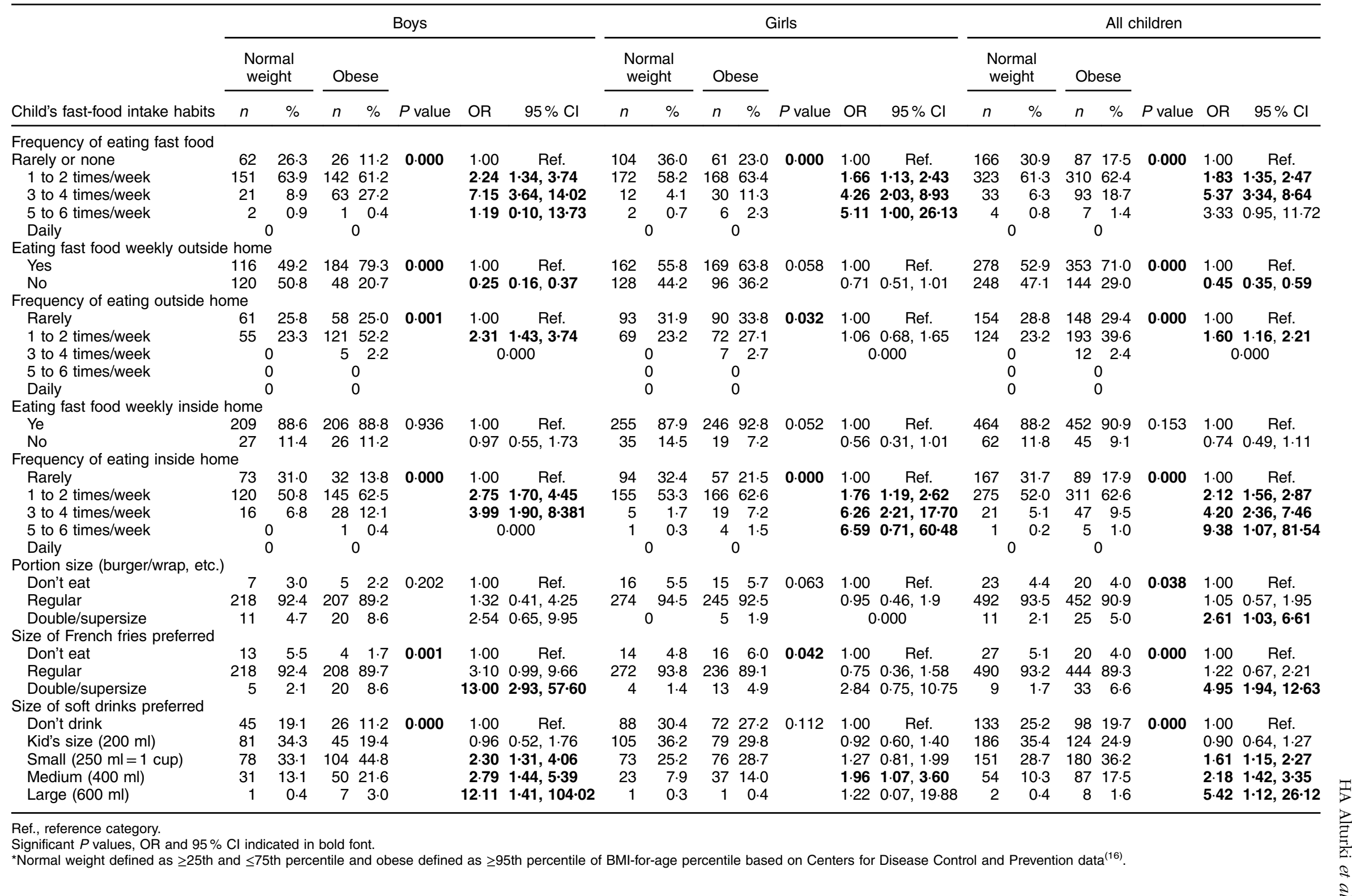


Table 3 Association of parent behaviours for child's intake from fast-food restaurants with child weight status, according to sex and categorisation as normal weight or obese ${ }^{\star}$, among children aged 9.00-11.99 years ( $n$ 1023), Riyadh, Saudi Arabia, December 2015-March 2016

\begin{tabular}{|c|c|c|c|c|c|c|c|c|c|c|c|c|c|c|c|c|c|c|c|c|c|}
\hline \multirow{3}{*}{$\begin{array}{l}\text { Parent behaviours for child's intake from } \\
\text { fast-food restaurants }\end{array}$} & \multicolumn{7}{|c|}{ Boys } & \multicolumn{7}{|c|}{ Girls } & \multicolumn{7}{|c|}{ All children } \\
\hline & \multicolumn{2}{|c|}{$\begin{array}{l}\text { Normal } \\
\text { weight }\end{array}$} & \multicolumn{2}{|c|}{ Obese } & \multirow[b]{2}{*}{$P$ value } & \multirow[b]{2}{*}{ OR } & \multirow[b]{2}{*}{$95 \% \mathrm{Cl}$} & \multicolumn{2}{|c|}{$\begin{array}{l}\text { Normal } \\
\text { weight }\end{array}$} & \multicolumn{2}{|c|}{ Obese } & \multirow[b]{2}{*}{$P$ value } & \multirow[b]{2}{*}{ OR } & \multirow[b]{2}{*}{$95 \% \mathrm{Cl}$} & \multicolumn{2}{|c|}{$\begin{array}{l}\text { Normal } \\
\text { weight }\end{array}$} & \multicolumn{2}{|c|}{ Obese } & \multirow[b]{2}{*}{$P$ value } & \multirow[b]{2}{*}{ OR } & \multirow[b]{2}{*}{$95 \% \mathrm{Cl}$} \\
\hline & $n$ & $\%$ & $n$ & $\%$ & & & & $n$ & $\%$ & $n$ & $\%$ & & & & $n$ & $\%$ & $n$ & $\%$ & & & \\
\hline \multicolumn{22}{|l|}{ Family normally eats fast-food meal together } \\
\hline Don't eat & 11 & 4.7 & 5 & $2 \cdot 2$ & 0.000 & 1.00 & Ref. & 24 & 8.3 & 18 & 6.8 & 0.769 & 1.00 & Ref. & 35 & $6 \cdot 7$ & 23 & 4.6 & 0.000 & 1.00 & Ref. \\
\hline Yes & 196 & $83 \cdot 1$ & 154 & $66 \cdot 4$ & & 1.73 & $0.58,5.08$ & 237 & 81.7 & 218 & $82 \cdot 3$ & & 1.22 & $0.64,2.32$ & 433 & $82 \cdot 3$ & 372 & 74.8 & & 1.30 & $0.75,2.25$ \\
\hline No & 29 & $12 \cdot 3$ & 73 & 31.5 & & 5.53 & $1 \cdot 76,17 \cdot 33$ & 29 & $10 \cdot 0$ & 29 & 10.9 & & 1.33 & $0.60,2.96$ & 58 & 11.0 & 102 & 20.5 & & 2.67 & $1.44,4.96$ \\
\hline \multicolumn{22}{|l|}{ Who normally orders the fast-food meal } \\
\hline Don't order & 8 & 3.4 & 8 & 3.4 & 0.000 & $2 \cdot 20$ & $0.64,7.54$ & 20 & 6.9 & 20 & 7.4 & 0.072 & 1.00 & Ref. & 28 & $5 \cdot 3$ & 28 & 5.7 & 0.000 & 1.00 & Ref. \\
\hline Child's mother & 88 & 37.3 & 68 & $29 \cdot 3$ & & 1.70 & $0.75,3.82$ & 70 & $24 \cdot 1$ & 81 & 30.6 & & 1.15 & $0.57,2.32$ & 158 & 30.0 & 149 & $30 \cdot 0$ & & 0.94 & $0.53,1.66$ \\
\hline Child's father & 78 & $33 \cdot 1$ & 58 & $25 \cdot 0$ & & 1.63 & $0.72,3.71$ & 140 & $48 \cdot 3$ & 125 & $47 \cdot 2$ & & 0.89 & $0.45,1.73$ & 218 & 41.4 & 183 & $36 \cdot 8$ & & 0.83 & $048,1.46$ \\
\hline Child him/herself & 40 & $16 \cdot 9$ & 88 & 37.9 & & 4.84 & $2 \cdot 09,11 \cdot 16$ & 33 & 11.4 & 29 & $10 \cdot 8$ & & 0.87 & $0.39,1.94$ & 73 & $13 \cdot 8$ & 117 & 23.5 & & 1.60 & $0.88,2.92$ \\
\hline Others & 22 & 9.3 & 10 & 3.3 & & 1.00 & Ref. & 27 & $9 \cdot 3$ & 10 & 3.8 & & 0.37 & $0.14,0.96$ & 49 & $9 \cdot 3$ & 20 & 4.0 & & 0.40 & $0.19,0.85$ \\
\hline \multicolumn{22}{|c|}{ Parent normally decides the type/size of the fast-food meal } \\
\hline Don't eat & 10 & $4 \cdot 2$ & 6 & $2 \cdot 6$ & 0.000 & 0.33 & $0.11,0.95$ & 15 & $5 \cdot 2$ & 16 & $6 \cdot 0$ & 0.233 & 1.51 & $0.69,3.31$ & 25 & 4.7 & 22 & 4.4 & 0.026 & 0.72 & $0.39,1.33$ \\
\hline Yes & 159 & 67.4 & 105 & $45 \cdot 3$ & & 0.36 & $0.24,0.53$ & 197 & 67.9 & 194 & 73.2 & & 1.39 & $0.93,2.07$ & 356 & $67 \cdot 6$ & 299 & $60 \cdot 2$ & & 0.69 & $0.52,0.90$ \\
\hline No & 67 & 28.4 & 121 & $52 \cdot 1$ & & 1.00 & Ref. & 78 & $26 \cdot 9$ & 55 & $20 \cdot 8$ & & 1.00 & Ref. & 145 & 27.5 & 176 & 35.4 & & 1.00 & Ref. \\
\hline \multicolumn{22}{|c|}{ Parent normally orders from 'healthy meals menu' } \\
\hline Don't eat & 26 & $11 \cdot 0$ & 15 & 6.5 & 0.000 & 1.00 & Ref & 42 & 14.5 & 27 & $10 \cdot 2$ & 0.245 & 1.00 & $\operatorname{Re}$ & 68 & $12 \cdot 7$ & 42 & 8.5 & 0.002 & 1.00 & Ref. \\
\hline Yes & 107 & $45 \cdot 3$ & 64 & $27 \cdot 6$ & & 1.03 & $0.51,2 \cdot 10$ & 132 & 45.5 & 134 & 50.6 & & 1.57 & $0.92,2.71$ & 239 & $45 \cdot 4$ & 198 & 39.8 & & 1.34 & $0.87,2.05$ \\
\hline No & 103 & $43 \cdot 2$ & 153 & 65.5 & & 2.57 & $1 \cdot 30,5.09$ & 116 & $40 \cdot 0$ & 104 & $39 \cdot 2$ & & 1.39 & $0.80,2.42$ & 219 & $41 \cdot 6$ & 257 & $51 \cdot 7$ & & 1.90 & $1 \cdot 24,2.90$ \\
\hline Parent occasionally offers fast-food resta & urant $n$ & meal a & s a re & eward & & & & & & & & & & & & & & & & & \\
\hline Don't eat & 12 & $5 \cdot 1$ & 5 & 2.2 & 0.159 & 1.00 & Ref. & 21 & $7 \cdot 2$ & 19 & $7 \cdot 2$ & 0.713 & 1.00 & Ref. & 33 & $6 \cdot 3$ & 24 & 4.8 & 0.317 & 1.00 & Ref. \\
\hline Yes & 102 & $43 \cdot 2$ & 113 & $48 \cdot 7$ & & $2 \cdot 65$ & $0.90,7.80$ & 150 & $51 \cdot 7$ & 146 & $55 \cdot 1$ & & 1.07 & $0.55,2.08$ & 252 & $47 \cdot 9$ & 259 & $52 \cdot 1$ & & 1.41 & $0.81,2.45$ \\
\hline No & 122 & $51 \cdot 7$ & 114 & $49 \cdot 1$ & & 2.24 & $0.76,6.56$ & 119 & $40 \cdot 1$ & 100 & 37.7 & & 0.92 & $0.47,1.82$ & 241 & $45 \cdot 8$ & 214 & $43 \cdot 1$ & & 1.22 & $0.69,2 \cdot 13$ \\
\hline Nutritio & staura & ant me & & & & & & & & & & & & & & & & & & & \\
\hline Don't eat & 10 & 4.2 & 5 & 2.2 & 0.016 & 1.00 & Ref. & 18 & $6 \cdot 2$ & 17 & 6.4 & 0.843 & 1.00 & Ref. & 28 & $5 \cdot 3$ & 22 & 4.4 & 0.250 & 1.00 & Ref. \\
\hline Yes & 27 & 11.4 & 25 & $10 \cdot 8$ & & 1.85 & $0.55,6 \cdot 17$ & 36 & $12 \cdot 4$ & 40 & $15 \cdot 1$ & & $1 \cdot 17$ & $0.52,2.62$ & 63 & $12 \cdot 0$ & 65 & $13 \cdot 1$ & & 1.31 & $0.68,2.53$ \\
\hline No & 52 & $22 \cdot 0$ & 83 & $35 \cdot 8$ & & 3.19 & $1.03,9.86$ & 67 & $23 \cdot 1$ & 55 & $20 \cdot 8$ & & 0.86 & $0.40,1.84$ & 119 & $22 \cdot 6$ & 138 & 27.8 & & 1.47 & $0.80,2.71$ \\
\hline Never & 108 & $45 \cdot 8$ & 83 & 35.8 & & 1.53 & $0.50,4.66$ & 123 & $42 \cdot 4$ & 107 & 40.4 & & 0.92 & $0.45,1.87$ & 231 & 43.9 & 190 & 38.2 & & 1.04 & $0.58,1.88$ \\
\hline Don't know & 39 & $16 \cdot 5$ & 36 & $15 \cdot 4$ & & 1.84 & $0.57,5.92$ & 46 & $15 \cdot 9$ & 46 & $17 \cdot 3$ & & 1.05 & $0.48,2 \cdot 30$ & 85 & $16 \cdot 2$ & 82 & $16 \cdot 4$ & & 1.22 & $0.65,2.31$ \\
\hline
\end{tabular}

Ref., reference category.

Significant $P$ values, $\mathrm{OR}$ and $95 \% \mathrm{Cl}$ indicated in bold font.

*Normal weight defined as $\geq 25$ th and $\leq 75$ th percentile and obese defined as $\geq 95$ th percentile of BMI-for-age percentile based on Centers for Disease Control and Prevention data ${ }^{(16)}$. 
obese groups. Parents who took their children to fast-food restaurants for 'no particular reason' was higher with normal-weight children, but only among the boys (OR $=$ $0 \cdot 47 ; 95 \%$ CI 0.25, 0.87; $P=0 \cdot 015$ ).

\section{Discussion}

Saudi Arabian society has undergone dramatic lifestyle changes in the past decade. Despite this, limited contemporary research exists on the fast-food consumption habits of Saudi Arabians, especially children. This current research highlights the prevalence of fast-food consumption factors among boys and girls, aged 9-12 years, in Riyadh. A high frequency of fast-food consumption was shown in both normal-weight and obese Saudi Arabian children, but weekly intakes of fast foods were much higher in the obese children. Moreover, logistic regression revealed that the knowledge, attitudes and practices of parents and their children towards the consumption of fast foods appeared to be associated with the occurrence of normal weight and/or obesity among Saudi Arabian children.

Socio-economic data from this cohort are described in detail in our previous study ${ }^{(24)}$. Briefly, parental education had no significant associations on children's weight. However, increased trends showed that the fathers of normal-weight boys frequently had a postgraduate education; the fathers of obese boys reported an undergraduate or diploma qualification as their highest level of education; high income was positively associated with families having a normal-weight child; and low to mid incomes were a higher risk factor contributing to families having an obese child. Interestingly, family homes that typically have a 'backyard' to do physical activity was a protective factor against obesity. Overall, we previously highlighted that increased health-conscious parental involvement with their child's diet may be a key factor in intervention management and dietary control. We showed a direct link between positive weight management and parents who actively adopt healthy food choices in the home. Our current data add to our previous publication on sociodemographic characteristics, by reporting the relationships between obesity and fast-food consumption.

In the current study, as expected, obese children consumed more fast food per week than normal-weight children. The average intake frequency of fast foods ranged between 1 and 2 times/week (61.3\% for normal weight, $62.4 \%$ for obese), significantly more obese children had a fast-food intake of 3-4 times/week (6.3\% for normal weight, $18.7 \%$ for obese) and more normal-weight children rarely consumed fast-foods compared with obese children (30.9\% for normal weight, $17.5 \%$ for obese). Our results are comparable with data on 5th and 6th grade Saudi Arabian boys in Al-Hassa, eastern Saudi Arabia ${ }^{(25)}$, where obese children consumed significantly more servings of fast foods. 
The evidence on the association between fast-food consumption and weight status in children is mixed. Some research shows a small, but important, positive correlation between fast-food consumption and increased BMI in children $^{(6,26)}$, while others have failed to support this correlation $^{(27,28)}$. In our study, while the obese group consumed fast foods more frequently than normal-weight children, the difference of 1-2 times/week was not significant between the groups. This may suggest that the frequency of fast-food intake is not the main cause of weight gain in school-aged children. However, the interaction of 'very frequent intake' of fast foods with other lifestyle and/or dietary factors may contribute to obesity among this age group ${ }^{(29)}$.

Our data clearly showed that obese children were more likely to consume fast foods outside the home (e.g. at a restaurant) than normal-weight children $(71.0 \% v .52 .9 \%)$. However, no statistically significant differences were found between groups if the fast food was consumed at home. Children aged less than 12 years are less likely eat outside their homes, without family supervision, compared with those over 12 years, who eat outside with their friends, especially boys, potentially being provided more freedom and independence. Interestingly, is appears that fast-food home delivery among the younger generation of Saudi Arabians is becoming increasingly popular. Therefore, it may not be unusual that more children, in both groups in our study, were eating fast foods inside the home.

The larger portion sizes available at fast-food restaurants is another aspect of concern, due to their higher density of dietary energy and fat content ${ }^{(30)}$. In the past decade, increased portion sizes available for consumers at fast-food restaurants has been reported, where increases of about two-to fivefold for burgers, French fries and soft drinks typically indicate a higher intake of dietary fat and energy $^{(31)}$. Our study showed that larger portion sizes of fast foods were significantly positively associated with a high risk of obesity among both boys and girls, and suggested that obese children were more willing to consume larger portion sizes, especially of French fries and soft drinks, than normal-weight children.

Parents directly influence the eating habits and nutrition behaviours of their children ${ }^{(32)}$, and play a critical role in dealing with, monitoring of and attitudes towards their children's eating habits ${ }^{(33)}$, including fast-food consumption. Our study showed that parents who regularly ate fast-food meals with their children, controlled the type and/or portion size for their children and ordered from the 'healthy meals menu' for their children were more likely to have normal-weight children, especially for boys. These may be considered as positive parental protective factors from obesity in our cohort. However, a study among 9-11year-olds reported that parents more involved in their child's fast-food selection did not necessarily have a positive impact on the children's food selection behaviours ${ }^{(34)}$. While healthier selection items are available at fast-food restaurants, not many children ordered these options. Provision of healthier product options in fast-food restaurants may not result in increased selection of these options ${ }^{(35)}$, parental intended reduction of energy intake for the child, or increased number of visits to a fast-food restaurant by a child consumer. Conversely, it could increase the chances of children selecting less-healthy choices $^{(36)}$. Encouraging parents in limiting outings to fastfood restaurants may be a better option towards preventing obesity rather than influencing their child's food choices from the menu.

Evidence for parental influence on fast-food choices and purchasing decisions is very scarce. Questions like the effects of permissive $v$. restrictive 'parenting styles' on children being overweight or obese, and whether parental intervention on food choice heightens child obesity, perhaps through inciting rebellious behaviour, remain unanswered ${ }^{(37,38)}$. In our cohort, children's fast-food intake was influenced by their parents. The parents of normal-weight children tended to be more involved in the selection of lower-energy-dense foods from a fast-food menu, which may positively influence the child's energy intake. Obese boys were more independent of parental influence when ordering from fast-foods outlets than normal-weight children. Children responsible for their own orders, in the absence of parental monitoring, tended to choose fast-food options with significantly higher energy and sugar content, and/or larger portion size. Similar results and views were reported in a recent unique Australian study, where children had the lowest energy content of foods purchased when parents controlled the selection of the fast-food meal ${ }^{(39)}$.

The potential influence of nutritional information on a fast-food menu on children's selection and resultant energy intake is not clear ${ }^{(40,41)}$. Our study focused on parental attitudes, rather than those of the participating children, due to their limited grasp on concepts of energy and fat. A review of thirty-one studies (six conducted in children and adolescents, twenty-five in adults) assessed the effectiveness of energy (calorie) labelling, at the point of purchase, at fast-food restaurants ${ }^{(42)}$. The authors reported a positive trend of energy labelling on purchase decisions; however, the best-designed studies showed that energy labels do not have the desired effect in reducing total energy ordered at the population level. More specifically, among children, a study in parents of school-aged children (6-11 years) found that nutritional labelling on restaurant menus increased parents' nutrition information awareness, but did not decrease energy purchased for either children or parents ${ }^{(40)}$. Therefore, the availability of nutritional information does not guarantee healthier food choices. Future research is required to determine the age where the provision of nutritional information may influence choices.

The majority of parents in our cohort did not notice nutritional labels in fast-food restaurants. While the 
regulations in Saudi Arabia require fast-foods outlets and restaurants to provide this information, it is not well followed or enforced. Saudi Arabian fast-food restaurants are not alone in this respect. In the USA, for example, of the 300 mega food chains, only about $50 \%$ offer nutritional information $^{(8)}$ and a parental-involved menu-labelling meta-analysis reported that energy labelling at restaurants weakly influences food choices ${ }^{(43)}$. Further studies are required to increase the evidence for the provision of nutritional information having an effect on fast-food consumption among children ${ }^{(44)}$.

Understanding the reasons why parents take their children to fast-food restaurants may assist in providing effective intervention strategies to minimise fast-food consumption and related health issues in children. Our study showed that most parents, for all groups, viewed fast-food restaurants as entertainment for their children; that the child was more likely to eat a full meal due to a taste preference for restaurant foods; and that this taste preference was significantly higher in the obese group, potentially due to the foods' high fat, sugar and sodium content. However, the price of fast-food restaurant meals influenced parents' decision to take their child, only with obese boys. A study among Saudi Arabian adolescent girls reported that the preferred taste at international food chains was a main factor to choose and enjoy this type of fast food; while price was the least important concern ${ }^{(14)}$.

Food prices and cost offered by fast-food restaurants are major concerns ${ }^{(8)}$ in determining choice of fast foods for younger consumers ${ }^{(45)}$. A systematic review of time series and household surveys found that restaurant sales were 'more responsive to price changes than any other food category, with a $10 \%$ increase in price associated with an $8.1 \%$ reduction in consumption, ${ }^{\text {(46) }}$. A study on price sensitivity among 9-10-year-old children, examining the relationship between pricing and high-fat, energy-dense food choices, found a negative correlation between the fast-food prices, and selection and intake ${ }^{(47)}$. Our study found that fast-food price and cost had a strong influence on consumption among obese children, especially boys, given that they visited fast-food outlets more than normalweight children. Implementation of fast-food company taxes in Saudi Arabia, as public protective policy, may increase the prices of menu foods at these restaurants and, subsequently, reduce the consumption of high-fat and energy-dense foods ${ }^{(48)}$, especially in frequent and highrisk obese consumers ${ }^{(49)}$.

In our study, parents of the obese group described the 'child-friendly' menus at fast-food outlets to be relatively influential. We showed trends, among parents of obese children, of adopting unhealthy dietary practices for their children (preferring fast-food restaurants for their cost, taste and child-friendly policies) without recognising the potential negative impact on their child's health. This was further supported by parents stating, in 'other reasons', that 'fast foods served as an escape from their usual home meals for the children'. This result was not surprising, as people make their food choices based on taste and cost first, and then 'health', especially among children and adolescents $^{(50)}$.

\section{Study limitations}

Information gathered during this research has great potential to add to the limited data about fast-food consumption factors in a society undergoing a nutrition transition $^{(51,52)}$. One of the limitations of the study is that data were based on self-reporting, although we made every effort to minimise any possible over- or under-reporting by the participants. Even though the questionnaire was sent to the family to complete at home, we took great care in ensuring that the purpose the study was plain and simple to understand, and its importance, and we went to great lengths to explain the questionnaire items through a detailed informed consent form and participant information sheet. We also provided a direct contact number for the first author and encouraged all participating parents to inquire about any unclear questions or concerns.

Although the study's cross-section design may be a limitation, the study cohort was clearly identified and selected. This helped to minimise the risk of bias associated with unblinded interviews. While some study variables appear to be more significant in boys than girls, all variables appear significant between groups. In addition, as fast-food consumption habits are perceived as unhealthy, it may be selectively under-reported and/or misreported due to the stigma of obesity and the young age factor ${ }^{(53,54)}$. In girls, who can be more sensitive than boys about their weight status, there may be a possibility of bias.

Participants' parents were asked about their role in their child's intake from fast-food restaurants, even if the children chose the fast-food meal themselves. Justifiably, it is challenging to accurately record the choices of the young participants under parental care if they ate at fast-food chains without their parent/guardian. Data were gathered from self-reporting, not from actual purchase data, with the possibility that some results 'may also have been influenced by social desirability bias, ${ }^{, 55)}$.

\section{Conclusion}

Our study is unique to Saudi Arabia in that it examines parents'/caregivers' behaviours and attitudes as factors that guide the child consuming fast foods in and outside the home. Parents who are cautious when buying fast foods for their children may act as a protective factor against obesity. We found a direct link between weight status in children and parents who proactively chose healthy foods at restaurants compared with those who did not. Understanding the effects of parental factors involved in children's decision to eat fast foods is essential in 
formulating and implementing health promotion and disease prevention programmes among children. Overall, our findings highlight: the urgent need for increased responsibility among parents/caregivers to make healthier food choices to promote a healthy lifestyle for their children; and that the price of fast foods is linked to obesity in children, showing that governmental intervention, by way of higher taxes on fast foods, may make fast-food consumption less attractive to frequent fast-food consumers.

\section{Acknowledgements}

Acknowledgements: The authors thank all parents and families involved in the study sample, as well as the children who contributed to this study and agreed to participate. Also, the authors thank all dietitians who helped in collecting the anthropometric data. Financial support: This research was supported by King Abdulaziz City for Science and Technology (Riyadh City, Saudi Arabia) (reference number 161-14/2-3604338). The funders had no role in the design, analysis or writing of this article. Conflict of interest: None. Authorship: H.A.A. and P.S.W.D. conceived of and designed the research, and statistically analysed and interpreted the data. Collection and assembly of data was done by H.A.A. All authors participated in writing and drafting of the paper, critically reviewing its content, and approved the final version of the manuscript submitted for publication. Ethics of buman subject participation: The study was approved by the Institutional Review Board (IRB) at the Ministry of Health in Saudi Arabia (approval number 15-336E). The Ethical Clearance for Research Involving Human Participants was reviewed and obtained from The University of Queensland Behavioural and Social Sciences Ethical Review Committee (BSSERC) (approval number 2015001629). In addition, permission to conduct the study at primary schools was obtained from the Ministry of Education in Riyadh. Written informed consent was obtained from parents/guardians of the children who participated in the study.

\section{References}

1. World Health Organization (2016) Report of the Commission on Ending Childhood Obesity. Geneva: WHO.

2. El Mouzan MI, Al Herbish AS, Al Salloum AA et al. (2012) Regional variation in prevalence of overweight and obesity in Saudi children and adolescents. Saudi J Gastroenterol 18 129-132.

3. El-Hazmi MAF \& Warsy AS (2002) The prevalence of obesity and overweight in 1-18-year-old Saudi children. Ann Saudi Med 22, 303-307.

4. El Mouzan MI, Foster PJ, Al Herbish AS et al. (2010) Prevalence of overweight and obesity in Saudi children and adolescents. Ann Saudi Med 30, 203-208.

5. Collison KS, Zaidi MZ, Subhani SN et al. (2010) Sugarsweetened carbonated beverage consumption correlates with BMI, waist circumference, and poor dietary choices in school children. BMC Public Health 10, 234.
6. Taveras EM, Berkey CS, Rifas-Shiman SL et al. (2005) Association of consumption of fried food away from home with body mass index and diet quality in older children and adolescents. Pediatrics 116, 518-542.

7. Powell LM \& Nguyen BT (2013) Fast-food and full-service restaurant consumption among children and adolescents: effect on energy, beverage, and nutrient intake. JAMA Pediatr 167, 14-20.

8. The Keystone Center (2006) The Keystone Forum on AwayFrom-Home Foods: Opportunities for Preventing Weight Gain and Obesity. Washington, DC: The Keystone Center.

9. Al-Othaimeen AI, Al-Nozha M \& Osman AK (2007) Obesity: an emerging problem in Saudi Arabia. Analysis of data from the national nutrition survey. East Mediterr Health J 13, 441-449.

10. Chiang PH, Wahlqvist ML, Lee MS et al. (2011) Fast-food outlets and walkability in school neighbourhoods predict fatness in boys and height in girls: a Taiwanese population study. Public Health Nutr 14, 1601-1609.

11. Schmidt M, Affenito SG, Striegel-Moore R et al. (2005) Fastfood intake and diet quality in black and white girls: the National Heart, Lung, and Blood Institute Growth and Health Study. Arch Pediatr Adolesc Med 159, 626-631.

12. General Authority for Statistics in the Kingdom of Saudi Arabia (2017) 2010 Census. http://www.stats.gov.sa/sites/default/ files/census2010-dtl-result.pdf (accessed March 2017).

13. Al-Hazzaa HM, Abahussain NA, Al-Sobayel HI et al. (2011) Physical activity, sedentary behaviors and dietary habits among Saudi adolescents relative to age, gender and region. Int J Behav Nutr Phys Act 8, 140.

14. Alfaris N, Al-Tamimi J, Al-Jobair M et al. (2015) Trends of fast food consumption among adolescent and young adult Saudi girls living in Riyadh. Food Nutr Res 59, 26488-26498.

15. The High Commission for the Development of Arriyadh, Arriyadh Development Authority (2017) Population Study of Riyadh City (1437H). http://www.ada.gov.sa/idc/groups/ publ ic/documents/ARADAResearches/007523.pdf (accessed March 2017).

16. Centers for Disease Control and Prevention (2000) Children's BMI. http://www.cdc.gov/n ccdphp/dnpa/bmi/ childrensBMI/aboutchildrensBMI.htm (accessed March 2017).

17. Fryar CD, Gu Q \& Ogden CL (2012) Anthropometric reference data for children and adults: United States, 2007-2010. Vital Health Stat 11 issue 252, 1-48.

18. OMRON Europe (2017) Omron BF511 Body Composition Monitor. http://www.omron-healthcare.com/en/products/ weightmanagement (accessed March 2017).

19. Talma H, Chinapaw MJM, Bakker B et al. (2013) Bioelectrical impedance analysis to estimate body composition in children and adolescents: a systematic review and evidence appraisal of validity, responsiveness, reliability and measurement error. Obes Rev 14, 895-905.

20. McCarthy HD, Cole TJ, Fry T et al. (2006) Body fat reference curves for children. Int J Obes (Lond) 30, 598-602.

21. Al-Hazzaa HM, Musaiger AO \& ATLS Research Group (2011) Arab teens lifestyle study (ATLS): objectives, design, methodology and implications. Diabetes Metab Syndr Obes 4, 417-426.

22. Musaiger AO, Al-Roomi K \& Bader Z (2014) Social, dietary and lifestyle factors associated with obesity among Bahraini adolescents. Appetite 73, 197-204.

23. Shim JS, Oh K \& Kim HC (2014) Dietary assessment methods in epidemiologic studies. Epidemiol Health 36, e2014009.

24. Alturki HA, Brookes DSK \& Davies PSW (2018) Obesity prevention interventions in Saudi Arabian children building the evidence base: an in-depth analysis of sociodemographic characteristics and dietary habits of obese and normal weight schoolchildren. Glob Epidemic Obes $\mathbf{6}$, http://dx.doi.org/10.7243/2052-5966-6-1.

25. Amin TT, Al-Sultan AI \& Ali A (2008) Overweight and obesity and their association with dietary habits, and sociodemographic characteristics among male primary 
school children in Al-Hassa, Kingdom of Saudi Arabia. Indian J Community Med 33, 172-181.

26. Rosenheck R (2008) Fast food consumption and increased caloric intake: a systematic review of a trajectory towards weight gain and obesity risk. Obes Rev 9, 535-547.

27. Boutelle KN, Fulkerson JA, Neumark-Sztainer D et al. (2007) Fast food for family meals: relationships with parent and adolescent food intake, home food availability and weight status. Public Health Nutr 10, 16-23.

28. Duncan JS, Schofield G, Duncan EK et al. (2008) Risk factors for excess body fatness in New Zealand children. Asia Pac J Clin Nutr 17, 138-147.

29. Braithwaite I, Stewart AW, Hancox RJ et al. (2014) Fast-food consumption and body mass index in children and adolescents: an international cross-sectional study. BMJ Open $\mathbf{4}$, e005813.

30. Livingstone MB \& Pourshahidi LK (2014) Portion size and obesity. Adv Nutr 5, 829-834.

31. Young LR \& Nestle M (2003) Expanding portion sizes in the US marketplace: implications for nutrition counseling. $J \mathrm{Am}$ Diet Assoc 103, 231-234.

32. Scaglioni S, Arrizza C, Vecchi F et al. (2011) Determinants of children's eating behaviour. Am J Clin Nutr 94, 6 Suppl, 2006S-2011S

33. Brown R \& Ogden J (2004) Children's eating attitudes and behaviour: a study of the modelling and control theories of parental influence. Health Educ Res 19, 261-271.

34. Stutts M, Zank G, Smith K et al. (2011) Nutrition information and children's fast food menu choices. J Consum Aff 45, 52-86.

35. Lesser LI, Kayekjian KC, Velasquez P et al. (2013) Adolescent purchasing behavior at McDonald's and Subway. $J$ Adolesc Health 53, 441-445.

36. Yoong S, Dodds P, Hure A et al. (2016) Healthier options do not reduce total energy of parent intended fast food purchases for their young children: a randomised controlled trial. Nutr Diet 73, 146-152.

37. Bowne M (2009) A comparative study of parental behaviors and children's eating habits. Infant Child Adolesc Nutr 1, $11-14$.

38. Wake M, Nicholson JM, Hardy P et al. (2007) Preschooler obesity and parenting styles of mothers and fathers: Australian national population study. Pediatrics 120, 1353-1357.

39. Wellard L, Chapman K, Wolfenden L et al. (2014) Who is responsible for selecting children's fast food meals, and what impact does this have on energy content of the selected meals? Nutr Diet 71, 172-177.

40. Tandon PS, Zhou C, Chan NL et al. (2011) The impact of menu labeling on fast-food purchases for children and parents. Am J Prev Med 41, 434-442.
41. Elbel B, Gyamfi J \& Kersh R (2011) Child and adolescent fast-food choice and the influence of calorie labeling: a natural experiment. Int J Obes (Lond) 35, 493-500.

42. Kiszko KM, Martinez OD, Courtney Abrams MA et al. (2014) The influence of calorie labelling on food orders and consumption: a review of the literature. $J$ Community Health 39, 1248-1269.

43. Harnack L \& French S (2008) Effect of point-of-purchase calorie labeling on restaurant and cafeteria food choices: a review of the literature. Int J Behav Nutr Phys Act 5, 51.

44. Hobin E, Lillico H, Zuo F et al. (2016) Estimating the impact of various menu labeling formats on parents' demand for fast-food kids' meals for their children: an experimental auction. Appetite 105, 582-590.

45. Epstein LH, Dearing KK, Handley EA et al. (2006) Relationship of mother and child food purchases as a function of price: a pilot study. Appetite 47, 115-118.

46. Andreyeva T, Long MW \& Brownell KD (2010) The impact of food prices on consumption: a systematic review of research on the price elasticity of demand for food. $A m J$ Public Health 100, 216-222.

47. Sturm R \& Datar A (2011) Regional price differences and food consumption frequency among elementary school children. Public Health 125, 136-141.

48. Khan T, Powell LM \& Wada R (2012) Fast food consumption and food prices: evidence from panel data on 5 th and 8th grade children. J Obes 2012, 857697.

49. Powell L \& Chaloupka F (2009) Food prices and obesity: evidence and policy implications for taxes and subsidies. Milbank Q 87, 229-257.

50. Swanson M, Schoenberg N, Davis R et al. (2013) Perceptions of healthful eating and influences on the food choices of Appalachian youth. J Nutr Educ Behav 45, 147-153.

51. Popkin B, Adair L \& Ng S (2012) Global nutrition transition and the pandemic of obesity in developing countries. Nutr Rev 70, 3-21.

52. Sibai A, Nasreddine L, Mokdad A et al. (2011) Nutrition transition and cardiovascular disease risk factors in Middle East and North Africa countries: reviewing the evidence. Ann Nutr Metab 57, 193-203.

53. Livingstone MB, Robson PJ \& Wallace JM (2004) Issues in dietary intake assessment of children and adolescents. $\mathrm{BrJ}$ Nutr 92, Suppl. 2, S213-S222.

54. Forrestal S (2011) Energy intake misreporting among children and adolescents: a literature review. Matern Child Nutr 7, 112-127.

55. Van de Mortel TF (2008) Faking it: social desirability response bias in self-report research. Aust J Adv Nurs 25, $40-48$. 